\title{
A qualitative study to explore how professionals in the United Kingdom make decisions to test children for a sickle cell carrier status
}

\author{
Melissa Noke ${ }^{\star, 1}$, Sarah Peters ${ }^{1}$, Alison Wearden ${ }^{1}$ and Fiona Ulph ${ }^{1}$
}

European guidelines recommend that, unless there are clear benefits of autosomal recessive carrier testing in childhood, it should be deferred to protect children's autonomous decision making. Although it is believed that children receive testing in the United Kingdom, it is unclear how or why professionals make decisions to provide tests. Semi-structured interviews were conducted with 25 professionals in the United Kingdom who advise about, and undertake, childhood sickle cell trait testing. Data were analysed using thematic analysis. Few professionals were aware of, or used, guidelines to inform testing decisions and instead, considered the reproductive and clinical relevance of testing, and autonomous rights of parents. Many professionals believed testing was important and readily offered it to parents. Professionals who discouraged testing were met with parental resistance and often provided testing when conflict was difficult to manage. Children were rarely considered to be capable of making decisions and few were engaged in discussions. When consulted, older children demonstrated interest, but younger children usually declined testing. Wide variation in testing advice emerged because of opposing beliefs about children's best interests and potential benefits or harms of testing. An explanation of how children's best interests should be determined in light of conflicting evidence regarding the psychosocial and clinical implications of carrier status is needed. Improved awareness of guidelines might encourage professionals to support the role of children in testing decisions. Strategies are also required to help professionals determine children's cognitive capacity and to protect children's future autonomy during discussions with persistent parents.

European Journal of Human Genetics (2016) 24, 164-170; doi:10.1038/ejhg.2015.104; published online 27 May 2015

\section{INTRODUCTION}

International guidelines discourage childhood carrier testing on the premise that carrier identification may cause psychosocial harm, ${ }^{1}$ remove the child's future autonomous decision making about when and whether to be tested, ${ }^{2-4}$ and has no immediate reproductive relevance $^{1}$ or medical benefit to the child. ${ }^{2}$ The argument for postponing testing becomes problematic when there are possible health consequences of a carrier status, ${ }^{2}$ for example, in the case of sickle cell trait (SCT), which confers rare possible clinical associations including haematuria, hyposthenuria, and exertional rhabdomyolysis due to hypoxia. ${ }^{5}$ However, clinical complications are contentious ${ }^{6,7}$ and there is little evidence that the implications require early SCT identification. If professionals do not regard SCT as medically significant, ${ }^{6}$ a situation could arise whereby parents are informed that their newborn might experience health difficulties associated with $\mathrm{SCT},{ }^{8}$ while concurrently being informed that older children do not require SCT testing on the basis it has no clear medical benefit.

Despite the general presumption against childhood carrier testing, there is flexibility in the acceptance of tests either when the child has informatively consented, ${ }^{9}$ or when parents or professionals believe it is in the child's best interests and has clear benefit. ${ }^{4,9}$ International guidelines advocate that children should be involved in testing and receive counselling to enable their wishes to be heard and to support them to make autonomous decisions. ${ }^{9}$ To demonstrate competence and be the main decision maker, children should understand relevant information ${ }^{10}$ and have the cognitive capacity and maturity to understand the implications of their decision. ${ }^{9}$ Yet it may be challenging to determine competence when there is no clear method of assessing $\mathrm{it}^{10}$ or age at which it develops, ${ }^{1}$ and although some children could have the ability to make decisions, they might disengage from the counselling process ${ }^{11}$ or struggle to verbalise a reason for their decision. ${ }^{12}$ If children are not deemed competent, decisions can be made on their behalf. Although collaborative decision making is encouraged, discerning children's best interests may be difficult for parents and professionals if they have competing views from the outset ${ }^{12-14}$ and the clinical ${ }^{5}$ and psychosocial implications ${ }^{15}$ of childhood carrier identification are unclear. When professionals and parents have differing opinions about testing, there is no agreement about who has the power to make decisions. Although the British Society for Human Genetics (BSHG) and European Society of Human Genetics (ESHG) suggest that professionals have responsibilities to protect children from decisions which are not in their best interests, 4,9 the British Medical Association advise that, as the natural decision makers, parents are best placed to make decisions for their child and their wishes should be respected. ${ }^{16}$

Children are believed to receive tests for some autosomal recessive carrier traits, ${ }^{17,18}$ yet few studies internationally have explored why testing is provided for some children ${ }^{14,19-21}$ but not for others, ${ }^{22}$ how

${ }^{1}$ School of Psychological Sciences, University of Manchester, Manchester, UK

*Correspondence: Dr M Noke, School of Psychological Sciences, University of Manchester, Coupland 1 Building, Oxford Road, Manchester M13 9PL, UK. Tel: +44 161 $3061752 ;$

E-mail: melissa.noke@manchester.ac.uk

Received 25 September 2014; revised 15 February 2015; accepted 15 April 2015; published online 27 May 2015 
professionals navigate guidelines ${ }^{20}$ and manage conflict with parents, ${ }^{14}$ or how they communicate with children about testing. ${ }^{11,23}$ Newborn screening (NBS) in England identifies around 9300 newborns with SCT annually. ${ }^{24}$ This can prompt parents to seek testing for older children, ${ }^{22}$ however, little is known about the childhood SCT testing processes. The current study aimed to explore how professionals across the United Kingdom make decisions to test children for SCT, with a view to examining the use of professional guidelines in decision making, management of discussions with parents and elictation of children's autonomous decision making.

\section{MATERIALS AND METHODS}

\section{Recruitment}

SC and Thalassaemia Centre managers were approached and asked to distribute information to professionals $(N=3)$. Professional members of the UK Sickle Cell and Thalassemia Association of Counsellors were contacted via letter regarding participation $(N=143)$. Each regional NBS coordinator in England $(N=9)$ approached Health Visitors/Newborn (HV/NB) screeners via email. General practitioners (GPs; $N=27$ ) who were affiliated with the NBS committee or the sickle cell society steering committee were approached by letter. A snowballing method of recruitment was utilised, whereby professionals approached colleagues regarding participation. Prospective participants were provided with information about the study via email and given the opportunity to ask questions. Consent was obtained before participation.

\section{Interviews}

Professionals participated in one semi-structured face-to-face or telephone interview lasting $\sim 44 \mathrm{~min}(28.27-76.89 \mathrm{~min})$. Interview schedules were piloted with two professionals and amended accordingly. Professionals were asked to discuss their experience of advising parents about, or undertaking, childhood SC carrier testing. The interviewer (MN) asked professionals to discuss awareness of testing guidance and to detail how testing decisions were made. Children were defined as those under the age of 16 years (the age at which legal competence is assumed in the United Kingdom). ${ }^{4}$ Interviews were audiorecorded and transcribed verbatim. Identifying information was removed.

\section{Ethical approval}

Ethical approval was granted for this study by the University of Manchester Research Ethics committee (UREC ref: 11312).

\section{Analysis}

This study used a realist framework to report the experiences of participants. Data were analysed using thematic analysis ${ }^{25}$ in NVivo version 9 (QSR International Ply Ltd., Doncaster, VIC, Australia). Coding was undertaken iteratively at the manifest level to explore the processes involved in childhood testing. Interviews were initially reviewed for familiarity and initial codes assigned to data patterns by MN. Themes were constructed based on emerging patterns of data and the final structure of the themes was overseen by researchers with expertise in qualitative methods (FU, SP, AW). Negative cases were sought to refine themes and data were saturated when new codes failed to emerge. Data reliability was checked using consistency coding. Code books including interview quotes and code descriptions (with inclusion and exclusion examples) were provided to two independent researchers (SR and AD). Agreement exceeded $70 \%$ for each theme, the required percentage deemed acceptable. $^{25}$

\section{RESULTS}

\section{Sample characteristics}

In total, 25 professionals ( 23 female) from seven of the eight regions of England and one region of Scotland participated: London $(N=3)$, East Midlands $(N=2)$, East of England $(N=4)$, North West $(N=6)$, North East $(N=2)$, West Midlands $(N=4)$, Yorkshire and Humber $(N=2)$, South West England $(N=1)$, West Scotland $(N=1)$. As classified by the NHS Sickle Cell and Thalasseamia Screening Programme, ${ }^{26} 16$ professionals worked in high SC prevalence (HP) regions, 5 worked in low SC prevalence regions (LP), and 4 worked across high and low SC prevalence regions (HP/LP). Professionals with the following roles participated: haemoglobinopathy nurse/counsellor $(N=13)$, health visitor/newborn screener $(N=7)$, haemoglobinopathy counsellor (antenatal; $N=2), \mathrm{GP}(N=1)$, haematologist $(N=1)$, genetic counsellor $(N=1)$. Of these, one was also a regional antenatal, newborn and child health screening team manager and five were SC and Thalassaemia Centre managers.

\section{Professional advice, training, and awareness of guidelines}

Advice provided to parents about testing was dictated largely by professionals' personal beliefs regarding the importance or irrelevance of testing; consequently professionals in the same region of the United Kingdom provided different advice to parents (see Table 1). No differences were apparent between professionals in high or low prevalence regions. Most professionals advised parents to receive testing for their children $(N=16,64 \%)$. Others discouraged testing $(N=6,24 \%)$ and a minority did not specifically provide advice but referred families to the GP for further information $(N=3,12 \%)$. Around half of the professionals $(N=12,48 \%)$ had received some type of specialist counselling training. Two professionals were familiar with and used the BSHG guidelines when considering testing. Others were unaware of specific childhood testing guidance and some assumed the SC NBS cascade policies covered childhood testing. Most valued the use of guidelines in informing decisions (eg, 'I think guidelines are good, we should not have to make these decisions' P2). Each professional's advice about testing, awareness of guidelines, and receipt of counselling training is detailed in Table 2 .

\section{Incidental and intentional testing}

Children's SCT status was either discovered via specific SCT testing or incidentally revealed through routine blood tests (eg, before surgery or at sexual health clinics). Professionals were aware of children being intentionally tested in SC and Thalassaemia Centres, Genetic Counselling services, at GP surgeries, children's hospitals, or in community or voluntary organisations. At sexual health clinics, children were informed that blood tests could detect SCT and were given the option of receiving results (without parent consent or involvement). In all other circumstances, parent consent was required and results were either conveyed to parents or to children in the company of parents. As the study aimed to respond to specific questions about how professionals make decisions to undertake childhood SCT tests, the

Table 1 Advice about childhood SCT testing provided to parents by professionals in regions of the United Kingdom

\begin{tabular}{lccc}
\hline & $\begin{array}{c}\text { Test child } \\
\text { (any age) }\end{array}$ & $\begin{array}{c}\text { Defer testing until } \\
\text { adulthood }\end{array}$ & $\begin{array}{c}\text { Seek further information } \\
\text { from a GP }\end{array}$ \\
\hline London & $\sqrt{ }$ & & \\
East Midlands & $\sqrt{ }$ & & $\sqrt{ }$ \\
East of England & $\sqrt{ }$ & $\sqrt{ }$ & \\
North West & $\sqrt{ }$ & $\sqrt{ }$ & \\
North East & & $\sqrt{ }$ & \\
West Midlands & $\sqrt{ }$ & $\sqrt{ }$ & \\
Yorkshire and & $\sqrt{ }$ & & \\
Humber & & $\sqrt{ }$ & \\
South West & & & \\
West of Scotland & & & \\
\hline
\end{tabular}

Abbreviations: GP, general practitioner; SCT, sickle cell trait. 
Table 2 Professionals' testing advice, awareness of guidelines, and counselling training

\begin{tabular}{|c|c|c|c|c|}
\hline & Role & Advice about childhood testing a & Awareness of guidelines & Counselling training \\
\hline 1 & Haemoglobinopathy counsellor (antenatal) & Defer testing & None & PEGASUS $\%$ antenatal \\
\hline 2 & Haemoglobinopathy nurse/counsellor & Seek testing & None & PEGASUS \\
\hline 3 & Haematologist & Defer testing & Thalassaemia guidelines & None \\
\hline 4 & Haemoglobinopathy nurse/counsellor & Seek testing & None & None \\
\hline 5 & Haemoglobinopathy nurse/counsellor & Seek testing & None & None \\
\hline 6 & Haemoglobinopathy nurse/counsellor & Seek testing & None & None \\
\hline 7 & Haemoglobinopathy counsellor (antenatal) & Defer testing & None & Antenatal \\
\hline 8 & Haemoglobinopathy nurse/counsellor & Defer testing & None & None \\
\hline 9 & HV/NB screener & Seek testing & None & PEGASUS \\
\hline 10 & HV/NB screener & See GP for information & None & None \\
\hline 11 & HV/NB screener & See GP for information & None & None \\
\hline 12 & HV/NB screener & Seek testing & None & None \\
\hline 13 & HV/NB screener & Seek testing & None & PEGASUS \\
\hline 14 & HV/NB screener & See GP for information & None & PEGASUS \\
\hline 15 & Haemoglobinopathy nurse/counsellor & Seek testing & None & Counselling course \\
\hline 16 & Haemoglobinopathy nurse/counsellor & Seek testing & None & PEGASUS \\
\hline 17 & HV/NB screener & Seek testing & None & None \\
\hline 18 & Haemoglobinopathy nurse/counsellor & Seek testing & None & PEGASUS \\
\hline 19 & Genetic Counsellor & Defer testing ${ }^{\mathrm{C}}$ & $\mathrm{BSHG}$ & Genetic counselling \\
\hline 20 & Haemoglobinopathy nurse/counsellor & Defer testing ${ }^{c}$ & $\mathrm{BSHG}$ & PEGASUS \\
\hline 21 & Haemoglobinopathy nurse/counsellor & Seek testing & None & PEGASUS \\
\hline 22 & $\mathrm{GP}$ & Seek testing & None & None \\
\hline 23 & Haemoglobinopathy nurse/counsellor & Seek testing & None & None \\
\hline 24 & Haemoglobinopathy nurse/counsellor & Seek testing & None & None \\
\hline 25 & Haemoglobinopathy nurse/counsellor & Seek testing & None & None \\
\hline
\end{tabular}

Abbreviations: GP, general practitioner; PEGASUS, Professional Education for Genetic Assessment and Screening.

${ }^{a}$ Advice provided to parents to either seek or defer testing.

beducation and training for professionals involved in antenatal and NBS (http://www. pegasus.nhs.uk).

cProfessional considers individual cases when advising about testing.

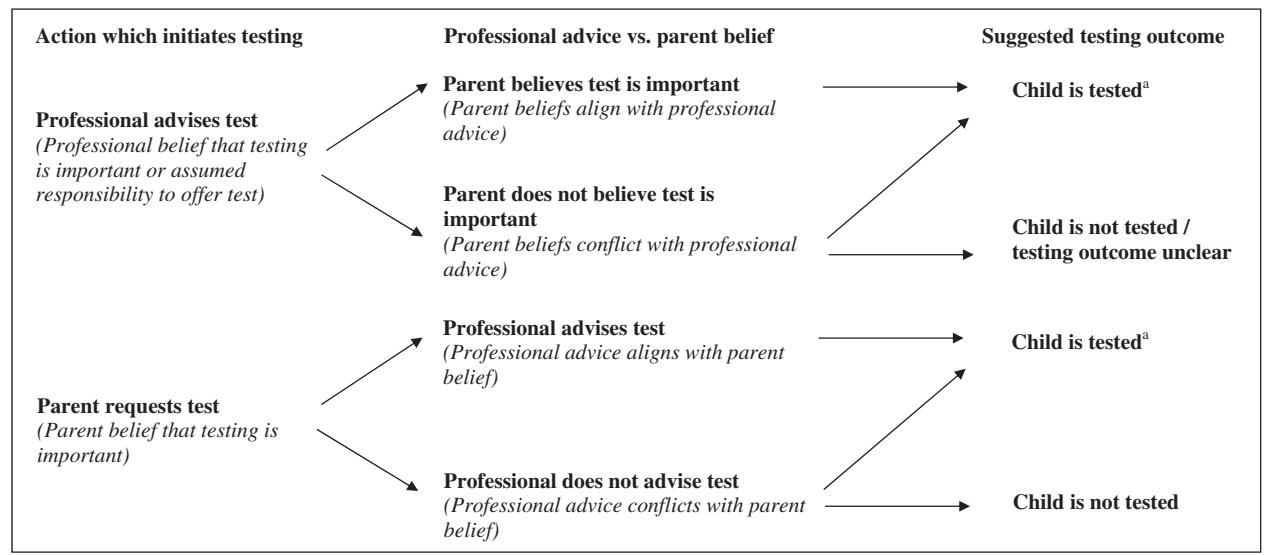

Figure 1 Diagram of the reported childhood SCT testing pathways. 'Influenced by children's autonomous decisions and professionals' capability to test.

decision-making process is discussed through three themes: (1) actions which initiate testing, (2) professional advice vs parent belief, (3) additional factors influencing suggested testing outcomes. A diagram representing the testing pathways is shown in Figure 1.

\section{Actions which initiate testing}

Professional advises test. Testing was frequently offered to parents by professionals who thought it could act as a safety net, either to provide reproductive information that may not be sought pre-conceptually or to incidentally identify asymptomatic children affected by SC disorder. Many professionals believed the health implications of SCT (mainly the potential for oxygen deficiencies during anaesthetic) necessitated testing during childhood. Consequently, SCT testing was thought to be more appropriate than testing for other 'more benign' traits (such as cystic fibrosis or other haemoglobin variants).

It could have implications on their health so that's the rationale for the siblings for sickle carrier sibling screening whereas if you've got haemoglobin D it's got no effect on your health (P17, HV/NB screener, LP).

Testing was also advised by professionals (eg, haemoglobinopathy nurses/counsellors) working in SC and Thalassaemia Centres 
(irrespective of their personal views about testing) because of an assumed inherent responsibility to follow the centre ethos- to identify carriers for the purposes of informed reproductive decision making in an inclusive 'cradle to grave' service. The 'test everyone philosophy' (associated with linked antenatal and NBS) reportedly failed to differentiate children from adults and there was little discussion about the appropriateness of testing minors.

R: Are there discussions about whether or not you should be testing the children?

P: Honestly no [laughs] no no no they don't, you know they, if a child randomly goes in for a blood test they'll do the test, if they don't they won't, we really encourage them, it's really my role, it falls within my remit, and if other professionals are going out to do various tests they will, but no no, they wouldn't, there isn't a guideline no (P18, haemoglobinopathy nurse/counsellor, HP)

A few professionals reported unease about discussing the appropriateness of testing (despite advising it) because of a suggested implicit recommendation from 'above' to suppress discouragement of testing. One professional felt testing should be deferred, but suggested that expressing this view could cause difficulties if overheard by colleagues.

It can cause a lot of controversy, some of my colleagues may not be happy with what I've said and so it yeah, it might cause upset, I don't have a problem with it but I know it can cause a lot of erm, it's very political [...] and then it causes that 'you shouldn't get involved in these research projects' arghhh because we've had these problems before in the past $[. .$.$] people want to express their$ opinions but it's the come back on them, that's what puts people off (P18, haemoglobinopathy nurse/counsellor, HP)

Parent requests test. Parents were instrumental in requesting carrier tests for children if NBS results had been forgotten or mislaid, when a younger sibling was identified through NBS as having SCT, or if the family transferred to the United Kingdom from overseas. Parents mostly wished to know the carrier status of their child 'just because they want to find out' (P4, haemoglobinopathy nurse/counsellor, HP), but also when they were concerned about the health of the child, or to determine paternity or arrange marriages.

Parents are thinking is that...you know some people know a lot more about the disease and think is it the disease or, you know that's quite a lot of my workload actually, is teenagers that do seem to exhibit more tiredness (P2, haemoglobinopathy nurse/counsellor, HP)

Every now and again, we'll get an underlying paternity test going on but yeah, we've had least one a year since I've been here (P5, haemoglobinopathy nurse/counsellor, HP)

\section{Theme 2. Professional advice $v s$ parent belief}

Professional advises test-parent does not believe test is important. When parents did not believe testing was important, some professionals suggested or recommended testing, but were hesitant to pressure parents. Others more strongly encouraged testing by emphasising the benefits to the parent of knowing the child's status (eg, to avoid the birth of a grandchild affected by SC) or making testing as accessible as possible (eg, through the immediate offer of testing).
Many parents reportedly agreed to testing when they 'realised (its) importance', or trusted the advice provided by an authoritative figure.

I think they take it up [testing] because they're offered it and because I think it's who they're offered it by so I think the fact that they're offered it by a trusted individual, they will do that (P22, GP, HP)

Parent requests test—professional discourages test. Professionals discouraged testing when they assumed it neglected children's autonomy, or assumed that clinical risks were modifiable and not sufficient justification for testing. When parents requested testing, professionals questioned parents' motives, discussed the importance of protecting the child's future autonomy, informed parents that SCT had no relevance until reproductive years, or conferred no clinical benefits. Parents were thought to have fundamental rights to discover whether their child had SCT, which created dissonance for those who discouraged testing, leaving them unhappy but feeling unable to refuse.

I would ask the family what the rationale was and what was the haste to find out and just at the end of the day obviously, it's a parental decision [...] I feel you have to do it for valid reasons but that's a personal view from my point of view, I just put the questions to parents (P7, haemoglobinopathy counsellor (antenatal), HP)

Some professionals recognised that if they refused testing, parents would likely seek and receive it elsewhere.

R: So who makes the final decisions in those kinds of situations?

P: I mean all we can do is advise. If the parents then wanted to go to their GP and the GP did the test then you know, that's out of our control. All we try to do is give enough information for the family to realise that you know it doesn't make any difference but at the end of the day if they wanted to go and ask for testing they're quite within their rights to do that (P8, haemoglobinopathy nurse/ counsellor, LP)

Two professionals working in Genetic Counselling services discouraged testing in line with BSHG guidelines and favourably viewed guidelines as protection from parent pressure.

There are occasions where maybe the professional can say 'well you know, this is not in the child's interest' and they will be supported by laws (P19, genetic counsellor, HP/LP)

Guidelines facilitated critical thought about the importance or harms of testing in individual cases and thus did not always restrict testing. Through consultation with colleagues, one professional agreed to test children if deemed necessary (eg, if a child was anxious), whereas the other could authorise tests at the hospital in rare cases.

\section{Theme 3. Factors influencing suggested testing outcomes}

Although those who discouraged or encouraged testing believed they had successfully dissuaded or persuaded parents, it was acknowledged that, as parents often failed to return to services, testing may have taken place elsewhere. In many cases, testing outcomes were influenced by the parent-professional discussion, however, they were also influenced by children's autonomous wishes and professionals' capability to provide tests.

Children's autonomous decisions. It was thought that children per se did not have capacity to consent and few professionals enlisted their 
wishes. Instead, decisions to test children were often made exclusively with parents (sometimes when the child was not present) following antenatal or NBS, or at opportunistic adult testing appointments. Parents were responsible for informing children about testing procedures, and it was not clear if children knew the purpose of tests.

$\mathrm{R}$ : Do the children take part in the process of deciding whether they can be tested?

P: The children don't because I speak to the parents (P23, haemoglobinopathy nurse/counsellor, HP)

When professionals did consult children, they typically did so when the child was deemed mature enough to participate, typically during teenage years. These 'older' children occasionally displayed interest in learning about their SCT status, but this was rarely the case for younger children (eg, 8 years), who were reportedly disengaged and refused testing. Testing was not undertaken when professionals 'ask the child and if they said no then they say no' (P8, haemoglobinopathy nurse/counsellor, HP). However, one professional suggested that:

If there's a child and they're you know, getting incontrollable just mentioning it [...] we can utilise the phlebotomist at the hospital 'cause then they can use the spray to numb the area, so you try and look for ways to make it as less [sic] traumatic as possible and then go from there (P5, haemoglobinopathy nurse/ counsellor, HP)

Professionals' capability to provide tests. Despite advising parents about testing, some professionals did not have the capability within their role to personally test children. Services followed different testing procedures, and although some professionals (such as haemoglobinopathy nurses/counsellors) provided SCT tests, others authorised tests at the hospital or referred the family to the GP or SC and Thalassaemia Centre. There was concern that GPs who were thought to lack knowledge about the haemoglobinopathies would provide inaccurate information.

[Parents] go and have a test done elsewhere but then they're not being followed up by specialists who understand about haemoglobinopathies or unusual haemoglobins so they don't get [...] counselling properly as to what that result means, because they could go and get that child tested and they might be a carrier of something other than what we've told them the other child is 'cause we don't know what else is in the family so that's probably what worries me. I'd rather follow them up all personally myself but my hands are tied... but we do have the odd case where they've been to the GP and got themselves tested and they have been given misinformation which for us is worrying (P20, haemoglobinopathy nurse/counsellor, HP)

Joint decisions were rarely described and when professionals disagreed, the more senior professional decided if the child could be tested. GPs were reportedly reluctant to provide tests and some professionals asserted their expertise to explain why testing was medically necessary.

We've had a couple of occasions where GPs haven't seen the need and I've had to phone the GPs and [...] explain to the GPs the process, because the GP's obviously can't take children's blood so in this area, the children have to get referred to paediatric outpatients for phlebotomy, so the GPs see it as a cost first and they also say 'oh it's not needed' and then I have to intervene [...] I'll phone the GP and I'll explain why or I'll write a letter explaining why it's necessary (P17, HV/NB screener, LP)

\section{DISCUSSION}

This is the first study that explores professionals' advice about childhood SCT testing and elucidates how testing decisions are made by professionals in the United Kingdom. This study has explored the views of professionals who have experience of testing children, as well as those who do not provide tests, but advise about testing. Advice was largely influenced by professionals' personal beliefs about the importance of childhood carrier identification. Yet views were polarised; some professionals who encouraged testing believed that SCT had medical implications, which warranted early testing in lieu of the child's future autonomy, whereas others who discouraged testing felt medical risks were slim or modifiable and preservation of the child's autonomy was necessary. The geographical variation in testing beliefs ${ }^{27}$ and advice suggests that parents in the same region of the United Kingdom may receive conflicting information about testing for their child. As advocated by guidance, ${ }^{4,9}$ professionals did consider children's 'best interests' when making decisions, however, their significantly different views highlight the ambiguity of this principle. ${ }^{28}$

Although the shift towards joint decision making between professionals and parents about the child's best interests has been increasingly recognised within some guidance, ${ }^{4,29}$ our data suggest that decision making was not collaborative in practise. Professionals described challenges of managing resistance from parents ${ }^{14}$ when they attempted to advocate the child's autonomy. ${ }^{12}$ Aligning with the British Medical Association ${ }^{16}$ and the premise of the 'zone of parental discretion', ${ }^{30}$ parents were believed to have fundamental rights to make testing decisions ${ }^{12}$ and some professionals consequently provided testing upon parental request despite advising that it should be deferred. ${ }^{14}$ Doing this maybe beneficial, as failure to test can create tension between parents and professionals, ${ }^{13,22}$ and be seen as negating the importance of taking action which is in the best interests of the family $^{30}$ or as failing to consider parents' knowledge of their child's best interests. ${ }^{16,31,32}$ Yet, although parents may have responsibilities for their child, the ESHG or BSHG do not suggest that parents have intrinsic rights over them and it is recommended that professionals should protect children from decisions that are not in their best interests and have no clear benefit. ${ }^{4,9}$

In line with the considerable debate regarding the 'not so benign' nature of SCT, ${ }^{7}$ professionals' views about the clinical severity of SCT sharply contrasted. ${ }^{6}$ The lack of consistent and available guidance about how to interpret the severity of the acknowledged health risks of SCT might be the cause of this disagreement. ${ }^{6}$ The SC NBS programme in England acknowledges the potential for 'rare health issues' associated with SCT and these, along with precautions to minimise risk, are communicated to parents. ${ }^{8}$ Awareness of this information within the SC NBS programme carrier leaflet might have prompted professionals to assume that these health risks justify 'clear benefits' of testing for older children. However, there is no specific guidance from the programme about whether this is the case and, without discernible evidence of medical benefit of early carrier identification, a precautionary approach to testing was adopted by other professionals. This is supported by the BSHG and ESHG, which advise that, without evidence of clear benefit, testing should not be undertaken in case of harm to children. ${ }^{1,2}$ As this position directly opposes the zone of parental discretion, which is bounded by the point at which harm is being done to the child, rather than simply 
non-maximisation of benefit', ${ }^{30}$ clarification of the benefits or harms of childhood carrier identification are needed.

To enable professionals to objectively consider the appropriateness of testing, it is important for guidelines to clarify whether testing can be argued to be in a child's best interests in light of the currently debated clinical complications of SCT and of the psychosocial implications of carrier identification. To do this might require discussion of whether the acknowledged potential health risks warrant a special case for universal childhood SCT testing or are considered 'free additional' benefits of NBS, which morally justify the provision of results for parents. ${ }^{7}$ If it is not thought that early identification of SCT is appropriate, it is important for professionals to understand the reasoning behind these paradoxical messages ${ }^{6}$ to ensure information is accurately communicated to parents. Existing research is not presently able to refute suggestions of psychosocial harms ${ }^{33}$ or to provide a true representation of the impact of carrier identification on children's well-being without understanding how factors such as social relationships (eg, family and peer) could influence individual responses to testing. ${ }^{15}$ To enable professionals to grapple ${ }^{34}$ with the psychosocial implications of carrier identification when making testing decisions, it is important for further research and subsequently guidance to clarify what, if any, negative psychosocial impacts there are of carrier identification. ${ }^{15}$ Guidelines may then be used flexibly to consider how children might individually respond to testing.

With the exception of the two professionals who were familiar with BSHG guidance, cases were not judged on individual merit and most professionals who received counselling training (eg, PEGASUS) did not report awareness of testing guidelines or of the issues involved in childhood testing. Critical thought is arguably beneficial to inform considered decision making ${ }^{34}$ when 'good practice depends upon the use of judgement in individual cases'. ${ }^{35}$ By reflecting on both the possible benefits and harms of testing, the perceived responsibility to encourage testing and to suppress the discouragement of testing may reduce, decreasing biased information-giving to parents-which is not conducive to informed choices or consent, ${ }^{36}$ does not take into consideration parents' autonomous wishes to defer testing ${ }^{12}$ and is described to be a paradox to the ethos of non-directive genetic counselling. ${ }^{13}$ However, as highlighted by our results, if testing is not provided, it might be sought elsewhere from professionals (such as GPs) who have less expertise. ${ }^{37}$ This is problematic if parents consequently misunderstand results ${ }^{18}$ and transmit this information to children.

Improved awareness of, and engagement with, the issues involved in childhood testing thus requires further emphasis on guidelines and their principles within training and continued professional development. This could also improve recognition of the pivotal role that children, when they have the appropriate capacity, should play in making decisions. ${ }^{1}$ Some professionals did recognise children's incremental decision-making powers, ${ }^{9}$ yet many did not to the 'greatest feasible extent ${ }^{\prime 9}$ include children in testing decisions. As children have changing and developing cognitive abilities ${ }^{38}$ and younger children (from 8 years) could have the ability to demonstrate competence if supported to do so, ${ }^{32}$ strategies to engage with children and determine competence might also be needed.

A limitation of this research is that other factors are likely to be involved in childhood testing, which were not captured by this study (eg, the practice of carrier testing could be variable within GP surgeries). A further limitation of this study is that many professionals failed to specify the age of the children they were referring to but, as reflected in the results, did allude to age when describing 'older' children making decisions.
This study reports on the wide variation in testing advice and suggested childhood SCT testing practices across the United Kingdom. Professionals were not predominantly aware of, and did not use, guidelines, despite receiving training, which covers the issue of childhood testing. The influence of personal beliefs on testing practice highlights the importance for guidelines to clarify the psychosocial harms and possible clinical benefits of SCT identification. Further discussion of these issues within professional training could reduce the subjectivities involved when professionals judge children's best interests. Improved awareness of guidance might minimise the assumed responsibility to provide testing and enable professionals to acknowledge children's rights to participate in decision making when competent.

\section{CONFLICT OF INTEREST}

The authors declare no conflict of interest.

\section{ACKNOWLEDGEMENTS}

We thank the professionals who gave their time for interview and second coders SR and AD.

1 Borry P, Evers-Kiebooms G, Cornel MC, Clarke A, Dierickx K: Genetic testing in asymptomatic minors: Background considerations towards ESHG Recommendations. Eur J Hum Genet 2009; 17: 711-719.

2 Ross LF, Saal HM, David KL, Anderson RR: Technical report: ethical and policy issues in genetic testing and screening of children. Genet Med 2013; 15: 234-245.

3 Borry P, Fryns JP, Schotsman P, Dierickx K: Carrier testing in minors: a systematic review of guidelines and position papers. Eur J Hum Genet 2006; 14: 133-138.

4 British Society for Human Genetics: Report of a Working Party of the British Society for Human Genetics. Birmingham, UK: British Society for Human Genetics, 2010.

5 Tsaras G, Owusu-Ansah A, Boateng FO, Amoateng-Adjepong Y: Complications associated with sickle cell trait: a brief narrative review. Am J Med 2009; 122: 507-512.

6 Miller FA, Paynter M, Hayeems RZ et al: Understanding sickle cell carrier status identified through newborn screening: a qualitative study. Eur J Hum Genet 2010; 18: 303-308.

7 Ross LF: Newborn screening for sickle cell disease: whose reproductive benefit? Eur J Hum Genet 2012; 20: 484-485.

8 NHS Screening Programmes. Information for mums and dads: Your baby carries a gene for sickle cell. Available at http://sct.screening.nhs.uk/leaflets.

9 Borry P, Cornel M, Evers-Kiebooms G et al: Genetic testing in asymptomatic minors: Recommendations of the European Society of Human Genetics. Eur J Hum Genet 2009; 17: 720-721.

10 Alderson P: Talking to children—and talking with them; in Clarke A (ed): The Genetic Testing of Children. Oxford, UK: BIOS Scientific Publishers Limited, 1998, pp 27-36.

11 Ulph F, Leong J, Glazebrook C, Townsend E: A qualitative study exploring genetic counsellors' experiences of counselling children. Eur J Hum Genet 2010; 18 : 1090-1094.

12 Arribas-Ayllon M, Sarangi S, Clarke A: Professional ambivalence: accounts of ethical practice in childhood genetic testing. J Genet Couns 2009; 18: 173-184.

13 Sarangi S, Clarke A: Constructing an account by contrast in counselling for childhood genetic testing. Soc Sci Med 2002; 54: 295-308.

14 Vears DF, Delany C, Gillam L: Carrier testing in children: exploration of genetic health professionals' practices in Australia. Genet Med 2014; 17: 380-385.

15 Wade $\mathrm{CH}$, Wilfond BS, McBride CM: Effects of genetic risk information on children's psychosocial wellbeing: a systematic review of the literature. Genet Med 2010; 12: 317-326.

16 British Medical Association: Medical Ethics Today: The BMA's handbook of ethics and law, 3rd edn. West Sussex, UK: Wiley-Blackwell, 2012.

17 Clarke A: The genetic testing of children-working party of the Clinical Genetics Society (UK). J Med Genet 1994; 31: 785-797.

18 Kai J, Ulph F, Cullinan T, Qureshi N: Communication of carrier status information following universal newborn screening for sickle cell disorders and cystic fibrosis: qualitative study of experience and practice. Health Technol Assess 2009; 13: 1-82.

19 Fryer A: Inappropriate genetic testing of children. Arch Dis Child 2000; 83: 283-285.

20 Multhaupt-Buell TJ, Lovell A, Mills L, Stanford KE, Hopkin RJ: Genetic service providers' practices and attitudes regarding adolescent genetic testing for carrier status. Genet Med 2007; 9: 101-107.

21 Borry P, Stultiens L, Goffin T, Nys H, Dierickx K: Minors and informed consent in carrier testing: a survey of European clinical geneticists. J Med Ethics 2008; 34: 370-374.

22 Ulph F, Cullinan T, Qureshi N, Kai J: Parents' responses to receiving sickle cell or cystic fibrosis carrier results for their child following newborn screening. Eur J Hum Genet 2014; 23: 459-465. 
23 Tse C, Sahhar M, Wallace J, Duncan RE: 'There's a whole different way of working with adolescents': interviews with Australian Genetic Counselors about their experiences with adolescent clients. J Genet Counsel 2013; 22: 674-684.

24 NHS Sickle Cell and Thalassaemia Screening Programme. Screening Programmes Sickle Cell and Thalassaemia Programme Review 2011/2012. Available at www.sct. screening.nhs.uk.

25 Boyatzis RE: Transforming Qualitative Information: Thematic Analysis and Code Development. Thousand Oaks, CA: Sage, 1998.

26 NHS Sickle Cell \& Thalassaemia Screening Programmes. Combined list of high prevalence and low prevalence Trusts. Available at http://sct.screening.nhs.uk/evaluationsreviewssurveys\#fileid 11806 .

27 Borry P, Goffin T, Nys H, Dierickx K: Attitudes regarding carrier testing in incompetent children: a survey of European clinical geneticists. Eur J Hum Genet 2007; 15: 1211-1217.

28 Plass AMC, Baars MJH, Cornel MC et al: Testing the Children: Do Non-Genetic HealthCare Providers Differ in Their Decision to Advise Genetic Presymptomatic Testing on Minors? A Cross-Sectional Study in Five Countries in the European Union. Genet Test Mol Biomarkers 2009; 13: 367-376.

29 Geelen E, Hoyweghen IV, Doevendans PA, Marcelis CLM, Horstman K: Constructing 'best interests': Genetic testing of children in families with hypertrophic cardiomyopathy. Am J Med Genet 2010; 155: 1930-1938.
30 Gillam L: Children's bioethics and the zone of parental discretion. Monash Bioeth Rev 2010; 29: 01-03.

31 Pelias MK: Genetic testing of children for adult-onset diseases: is testing in the child's best interest? Mt Sinai J Med 2006; 73: 605-608.

32 Gillot J: Childhood testing for a carrier status: the perspective of the Genetic Interest Group; in Clarke A (ed): The Genetic Testing of Children. Oxford, UK: BIOS Scientific Publishers Limited, 1998, pp 97-102.

33 British Medical Association Ethics Department: Medical Ethics Today The BMA's Handbook of Ethics and Law, 3rd edn. West Sussex, UK: Wiley-Blackwell. 2012.

34 Fenwick A: Are guidelines for genetic testing of children necessary? Fam Cancer 2010; 9: 23-25.

35 Parker M: Genetic testing in children and young people. Fam Cancer 2010; 9: 15-18.

36 Raffle AE: Information about screening-is it to achieve high uptake or to ensure informed choice? Health Expect 2001; 4: 92-98.

37 Vansenne F, de Borgie CA, Legdeur M, Spauwen MO, Peters M: Providing genetic risk information to parents of newborns with sickle cell trait: role of the general practitioner in neonatal screening. Genet Test Mol Biomarkers 2011; 15: 671-675.

38 Metcalfe A, Plumridge G, Coad J, Shanks A, Gill P: Parents' and children's communication about genetic risk: a qualitative study, learning from families' experiences. Eur J Hum Genet 2011; 19: 640-646. 